\title{
COVID-19: DU LỊCH BẢO TÀNG THU HÚT ĐÔNG ĐẢO LƯợNG KHÁCH "ONLINE"
}

\author{
Dinh Thi Tuyet, Nguyen Thi Thu Thuy, Do Van Phuc, Tran Viet Hoang, Nguyen Thi Thanh Nhan
}

\author{
Đại học Quốc gia Hà Nội, Việt Nam
}

Hà Nội , ngày 13/12/2021

Preprint DOI: https://osf.io/gu3fj/

Du lịch văn hóa luôn là loại hình được nhiều du khách yêu thích. Khai thác giá trị của các bảo tàng chính là ưu điểm chính trong việc phát triển loại hình du lịch này. Nếu chúng ta biết trân trọng, đầu tư, khai thác, phát huy tiềm năng của từng bảo tàng một cách khoa học và đúng cách thì sẽ tạo ra những sản phẩm du lịch văn hóa đa dạng, hấp dẫn, thu hút ngày càng nhiều khách tham quan. Và đặc biệt sẽ đem lại hiệu quả nhất định là việc đóng góp cho nền kinh tế Việt Nam.

Việt Nam được biết đến là 1 địa điểm du lịch với hệ thống bảo tàng đa dạng, hấp dẫn du khách. Thực tế cho thấy việc gắn kết du lịch với bảo tàng [1], di tích hiện nay là việc làm cần thiết để thu hút khách du lịch, góp phần quảng bá hình ảnh, văn hóa dân tộc và phát huy các giá trị của bảo tàng, di tích, đồng thời, thúc đẩy sự phát triển kinh tế. Bảo tàng là nơi lưu giữ những giá trị văn hóa, lịch sử của dân tộc qua các thời kỳ hình thành và phát triển một cách tương đối đầy đủ nhất. Đồng thời, đây là nơi bảo quản và trưng bày hàng ngàn hiện vật quý được sưu tầm từ thời xa xưa đến ngày nay. Cùng với màu sắc sáng tạo độc đáo phản ánh tinh hoa văn hóa truyền thống của các dân tộc Việt Nam được lưu giữ lại, mỗi bảo tàng lại có một cách sáng tạo khác nhau.

Du lịch bảo tàng được xem như con đường ngắn nhất trong việc tìm hiểu văn hóa, lịch sử của mỗi quốc gia, mỗi dân tộc. Dịch bệnh COVID-19 đã ảnh hưởng nặng nề đến ngành du lịch [2], [3]. Nhưng trong thời kì dịch bệnh bùng phát mạnh như hiện nay thì du lịch bảo tàng lại càng được người dân ưu tiên và lựa chọn nhiều hơn. Nhưng nó không chỉ là việc đến tham quan trực tiếp các hiện vật tại bảo tàng mà 
các bảo tàng đã đưa ra những cách tiếp cận mới phù hợp với tình hình dịch bệnh cũng như nhu cầu tham quan, du lịch của du khách.

Trong đại dịch Covid-19, hệ thống bảo tàng cũng không thể tránh khỏi những ảnh hưởng đó, cũng đã phải tạm dừng cho công tác phòng chống bệnh dịch [3]. Các hoạt động của bảo tàng được thực hiện chủ yếu bằng hình thức tuyên truyền, cổ động trực quan.

Tuy nhiên, khi dịch bệnh cơ bản được kiểm soát, Việt Nam đã cho phép mở cửa đón khách trở lại, các bảo tàng vẫn thận trọng, thậm chí dè dặt. Nhiều bảo tàng lớn, bình thường là địa điểm hấp dẫn đối vs du khách vẫn chưa có chủ trương mở cửa vì họ lo sợ nếu mở cửa vào thời gian này đi khách vẫn còn e ngại và chưa muốn đến tham quan ngay việc mở cửa bảo tàng phụ thuộc rất nhiều vào tâm lý khách hàng. Dù được phép tham quan, khách hàng cũng phải có thời gian "chững" lại để nắm bắt tình hình, không thể ngay lập tức đưa cả gia đình hay cơ quan, đơn vị đến chỗ đông người. Vì vậy, việc đánh giá xu hướng khách hàng trong thời điểm này là cần thiết, trước khi đưa ra quyết định cuối cùng của các bảo tàng.

Công tác chuẩn bị cho ngày đầu mở cửa của các bảo tàng thật sự khó khăn. Các bảo tàng sẽ rà soát và phải tổng vệ sinh, phun khử khuẩn, chuẩn bị máy đo thân nhiệt, mã QR để khai báo y tế... Đối với đoàn khách tham quan từ 20-30 người, đơn vị sẽ chia nhỏ đoàn khách. Nhân viên sẽ trực tại các khu vực trưng bày để nhắc nhở khách giữ khoảng cách, tuân thủ Thông điệp $5 \mathrm{~K}$ của Bộ Y tế. Để tránh khỏi nhiều sự phức tạp của bệnh dịch vừa có thể khai thác tốt lượng khách tham quan; nhiều bảo tàng đã tìm lối đi riêng cho mình.

Hệ thống bảo tàng Việt Nam đã từng bước thay đổi, tiếp cận du khách mới mẻ, cũng góp phần đa dạng hóa các hoạt động để tạo ra những sản phẩm hấp dẫn, mang lại những trải nghiệm khác biệt, góp phần thu hút khách tham quan. Các bảo tàng hiện nay rất đông khách "online” [4]. Đó là nhờ việc nhờ việc ứng dụng công nghệ trong trưng bày và giới thiệu trưng bày, làm tăng khả năng kết nối, tương tác cũng như cung cấp thông tin về kho tư liệu, hiện vật quý hiếm đang lưu giữ tại bảo tàng.

Một số bảo tàng quốc gia, bảo tàng chuyên ngành và bảo tàng cấp tỉnh đã từng bước đổi mới trưng bày theo định hướng tăng cường các hiện vật gốc cũng như áp dụng các phương tiện khoa học kỹ thuật (như màn hình cảm ứng, kỹ thuật $3 \mathrm{D} . .$. ) để làm phong phú và hấp dẫn nội dung trưng bày; Đồng thời tăng cường các hoạt động, các chương trình trải nghiệm, giáo dục di sản văn hóa theo cách tiếp cận 
mới để tăng thêm sự hấp dẫn đối với công chúng, trong đó, đối tượng học sinh sinh viên được xem là một trong những đối tượng chính của các hoạt động này.Các bảo tàng đi đầu trong xu hướng này có thể đến như Bảo tàng Lịch sử quốc gia, Bảo tàng Dân tộc học Việt Nam, Bảo tàng Phụ nữ Việt Nam, Bảo tàng Văn hóa các dân tộc Việt Nam... Thay vì nghĩ đến bảo tàng chỉ là nơi giới thiệu lại tiến trình lịch sử, các nền văn hóa... một cách thụ động và đơn thuần với việc nghe, nhìn, tìm hiểu thông tin qua thuyết minh, việc hướng đến xây dựng một bảo tàng động qua việc sử dụng công nghệ tiên tiến và đa dạng hóa các hình thức trải nghiệm thực tế cho khách tham quan có lẽ là hướng đi tất yếu [5].

Bảo tàng Lịch sử Quốc gia chính là bảo tàng đầu tiên ở Việt Nam ứng dụng công nghệ tương tác ảo 3D (tương tác thực tại ảo) trong giới thiệu trưng bày. Bảo tàng Lịch sử quốc gia giới thiệu 3 sản phẩm từ ứng dụng công nghệ, đưa vào hoạt động và giới thiệu tới công chúng. Đầu tiên là nghiên cứu, nâng cấp ứng dụng $3 \mathrm{D}$ và hoàn thiện giới thiệu trưng bày tương tác ảo $3 \mathrm{D}$ chuyên đề "Bảo vật quốc gia". Việc đổi mới hình thức giới thiệu mang lại cho công chúng sự tương tác, trải nghiệm khác biệt, mới lạ và sâu sắc hơn. Khách tham quan trưng bày tương tác ảo phát trên nền tảng trực tuyến Zoom.

Tiếp theo là sản phẩm tham quan bảo tàng trực tuyến (Tourday online) miễn phí. Hình thức tham quan được kết hợp giữa thuyết minh với ứng dụng công nghệ 3D trên website của bảo tàng. Đặc biệt, khác với tham quan $3 \mathrm{D}$ thông thường, khách tham quan được tương tác trực tiếp với người hướng dẫn thông qua voice chat và boxchat góp phần tạo sự hứng khởi, sôi động cho khách tham quan. Bên cạnh đó, "Giờ học lịch sử" và "Câu lạc bộ Em yêu lịch sử" là hoạt động giáo dục hiệu quả, thu hút đông đảo học sinh, trẻ em tham gia. Đây là mô hình đã trở thành "thương hiệu" của Bảo tàng Lịch sử quốc gia. Trong điều kiện giãn cách xã hội, học sinh không thể tham gia trực tiếp nên đã từng bước chuyển hướng sang hình thức online. Đây là hướng hoạt động phù hợp với thực tiễn, tạo sân chơi vui học bổ ích cho các em học sinh, góp phần quảng bá, giới thiệu các di sản văn hóa của dân tộc.

Việc phát triển việc du lịch tham quan bảo tàng kiểu "mới” này tại Việt Nam đem lại rất nhiều trải nghiệm mới. Trước tiên, khi đến với tham quan Bảo tàng, du khách sẽ có những trải nghiệm với hướng dẫn viên kiểu mới. Từ trước đến nay, tại các hệ thống bảo tàng trong nước, khách tham quan thường phải nhờ đến sự hỗ trợ thông tin từ các hướng dẫn viên hoặc người thuyết minh thì giờ đây, du lịch “online” cùng bảo tàng có thể mang đến cho du khách những trải nghiệm chủ động, tân tiến và thú vị hơn với audio guide. Khách tham quan có thể đăng ký sử dụng audio guide - một thiết bị đi kèm tai nghe thuyết minh với hai ngôn ngữ: Tiếng Việt và tiếng Anh. 
Bên cạnh những trải nghiệm khi được tham quan và chứng kiến những giá trị lịch sử được trưng bày trong bảo tàng quan màn hình công nghệ, du khách có thể tự mình chụp lại những bức ảnh lưu niệm của những khoảnh khắc trong khi trải nghiệm tham quan bảo tàng [5].

Với thực trạng như hiện nay, còn rất nhiều bảo tàng “online” ở nước ta chưa thực sự phát huy được các giá trị và chưa được lựa chọn là điểm đến đối với du khách [6]. Trong việc phát triển du lịch văn hóa, rất cần có thêm các bảo tàng hấp dẫn góp phần tăng thêm thời gian lưu trú và chi tiêu của khách du lịch.

Mỗi bảo tàng, với những đặc thù riêng có, cần sớm có kế hoạch thực hiện cụ thể phù hợp để tạo ra những điểm nhấn. Các bảo tàng cần quan tâm: Đổi mới nội dung và hình thức trưng bày hiện vật; đa dạng hóa các sự kiện hoạt động, quan tâm trưng bày/ tổ chức triển lãm chuyên đề, đề cao tính tương tác với công chúng. Về cơ bản, du lịch bảo tàng cần có "chất" để thu hút khách du lịch. Chất ở đây chính là những tri thức quý giá về văn hóa nói chung và văn hóa của từng lĩnh vực nói riêng của khoa học và rất cần phổ biến cho công chúng. Trong thời gian qua, rất nhiều nhà khoa học Việt Nam đã đóng góp cho nhân loại nhiều công trình khoa học có giá trị cao về văn hóa, như tính cộng văn hóa [7], [8] do Giáo sư Vương Quân Hoàng và các cộng sự nghiên cứu. Còn riêng cụm công trình về văn hóa môi trường [9]-[12], ông và các cộng sự có rất nhiều phát hiện thú vị như nguyên lý bán dẫn.vvv. Những tri thức khoa học về văn hóa cần được lồng vào các hiện vật, tranh ảnh sẽ giúp "nâng chất" dịch vụ của du lịch bảo tàng. Chắc chắn, việc nâng cao chất lượng, hoạt động của bảo tàng để thu hút khách nghĩa phải gắn với thị trường khách. Các bảo tàng cần xác định được đối tượng khách trước mắt và lâu dài để có giải pháp đầu tư phù hợp. Có những bảo tàng bước đầu nên tập trung thu hút khách là học sinh, sinh viên; tạo bước đệm hướng đến thu hút khách du lịch [13].

Ứng dụng công nghệ thông tin vừa tăng tính hấp dẫn cho bảo tàng, hoạt động trải nghiệm cho du khách, vừa giúp giải quyết tình trạng thiếu hướng dẫn viên tại điểm, nhất là về vấn đề ngôn ngữ,....[14]. Các bảo tàng cần tiếp tục triển khai số hóa các câu chuyện gắn với các hiện vật, nhờ sự hỗ trợ của công nghệ (thực tế ảo, thực tế ảo tăng cường, các ứng dụng (app), thuyết minh tự động...), có thể dễ dàng truyền tải bằng nhiều ngôn ngữ tới khách hàng phù hợp và tăng tính hấp dẫn, thú vị cho các hiện vật được trưng bày. 
Công tác truyền thông phải được chú trọng hơn nữa; kết nối và chủ động cung cấp thông tin với cơ quan báo chí, câu lạc bộ nhà báo du lịch. Bảo tàng cần liên kết chặt chẽ hơn với các doanh nghiệp lữ hành, cơ sở lưu trú du lịch trong việc quảng bá về các trang web, buổi trưng bày “online” bảo tàng, để làm phong phú thêm lượng du khách [15]. Chủ động, tăng cường liên kết với các trường học, cơ sở đào tạo. Với lớp học online tìm hiểu về lịch sử, văn hóa về Việt Nam, bảo tàng chắc hẳn sẽ cung cấp những thông tin sống động, tạo hứng thú cho các học sinh, sinh viên.

\section{Tài liệu tham khảo}

[1] G. Linh, "Gắn bảo tàng với phát triển du lịch - Hướng đi tất yếu," Bộ văn hóa, thể thao và du lich, 2019. https://bvhttdl.gov.vn/gan-bao-tang-voi-phat-trien-du-lich-huong-di-tat-yeu20190208153545597.htm (accessed Dec. 13, 2021).

[2] N. T. T. Thuy, N. T. T. Nhan, T. V. Hoang, and D. Van Phuc, "Tác động của dịch bệnh covid-19 đến ngành du lịch việt nam,” OSF Prepr., 2021, doi: 10.31219/osf.io/bjdek.

[3] V. La et al., "Policy response, social media and science journalism for the sustainability of the public health system amid COVID-19 outbreak: The Vietnam lessons," Sustainability, vol. 12, pp. 1-35, 2020.

[4] T. A. Trần, “Ảnh hưởng của công nghệ thực tế ảo đến lựa chọn điểm du lịch, giải pháp tăng cường phát triển du lịch Đà Nẵng hậu Covid-19,” 2020.

[5] Q. T. Trần, "Một số giải pháp nhằm phát triển du lịch tại khu di tích Đông Yên Tử." Đại học Dân lập Hải Phòng, 2019.

[6] T. N. D. Lý, "Bảo tàng, cộng đồng và du lịch Hướng tới bảo tồn di sản văn hóa và phát triển du lịch bền vững,” 2018.

[7] Q.-H. Vuong et al., "Cultural evolution in Vietnam's early 20th century: A Bayesian networks analysis of Hanoi Franco-Chinese house designs," Soc. Sci. Humanit. Open, vol. 1, no. 1, p. 100001, 2019, doi: 10.1016/j.ssaho.2019.100001.

[8] Q. H. Vuong et al., "Cultural additivity: behavioural insights from the interaction of Confucianism, Buddhism and Taoism in folktales," Palgrave Commun., vol. 4, no. 1, 2018, doi: 10.1057/s41599-018-0189-2. 
[9] Q. H. Vuong, "The semiconducting principle of monetary and environmental values exchange," Econ. Bus. Lett., vol. 10, no. 3, pp. 284-290, 2021, doi: 10.17811/ebl.10.3.2021.284-290.

[10] Q.-H. Vuong, "Western monopoly of climate science is creating an eco-deficit culture," Econ. L. Clim. Insight, pp. 1-9, 2021.

[11] Q. H. Vuong et al., "On the environment-destructive probabilistic trends: A perceptual and behavioral study on video game players," Technol. Soc., vol. 65, no. January, p. 101530, 2021, doi: 10.1016/j.techsoc.2021.101530.

[12] Q. Vuong, "From children's literature to sustainability science, and young scientists for a more sustainable Earth,” J. Sustain. Educ., vol. 24, no. December, 2020.

[13] M. An, "Bảo tàng không chỉ là nơi trưng bày hiện vật," Báo Nhân Dân, 2015. https://nhandan.vn/binh-luan-phe-phan/bao-tang-khong-chi-la-noi-trung-bay-hien-vat244000 (accessed Dec. 13, 2021).

[14] T. H. L. Nguyễn, "Bảo tàng, di tích tăng cường ứng dụng công nghệ: Biến nguy thành cơ."

[15] N. T. K. Cúc, "Xây dựng mô hình từ điển địa danh lịch sử-Văn hoá hà nội và ứng dụng trên thiết bị di động phục vụ phát triển du lịch,” in PROCEEDINGS, 2020, vol. 15, no. 3. 